\title{
General Education Learning Outcomes and Demographic Correlates in University Students in Hong Kong
}

\author{
Lu Yu ${ }^{1}$ (D) Daniel T. L. Shek ${ }^{1,2,3,4,5} \cdot$ Xiaoqin $Z h u^{1}$
}

Received: 3 September 2017 / Accepted: 1 June 2018 /Published online: 20 June 2018

(C) The Author(s) 2018

\begin{abstract}
Although there are studies showing that higher education would benefit university students, empirical research that comprehensively assesses student general education learning outcomes and related demographic correlates based on longitudinal data is minimal, especially in the Chinese context. To address the research gaps, the present study was conducted to investigate learning outcomes amongst university students in one university in Hong Kong based on a four-year longitudinal design $(N=460)$. Four dimensions of student general education learning outcomes were measured, including effective reasoning and problem solving, leadership, moral character, and integration of learning. Results suggested a U-shaped pattern of student learning outcomes for most dimensions, with no improvement or even a decrement in the second year and a steady growth thereafter. While family background did not affect student development, gender showed a significant moderating effect on students' development in two dimensions (i.e., effective reasoning and problem solving, and integration of learning). These findings suggest that students benefit from general education-embedded university study in multiple dimensions, especially after the first year of transition period. Practical implications of the findings and future research directions were also discussed.
\end{abstract}

$\mathrm{Lu} \mathrm{Yu}$

lu.yu@polyu.edu.hk

1 Department of Applied Social Sciences, The Hong Kong Polytechnic University, Hunghom, Hong Kong, People's Republic of China

2 Centre for Innovative Programmes for Adolescents and Families, The Hong Kong Polytechnic University, Hong Kong, People's Republic of China

3 Department of Social Work, East China Normal University, Shanghai, People's Republic of China

4 Kiang Wu Nursing College of Macau, Macau, People's Republic of China

5 Division of Adolescent Medicine, Department of Pediatrics, Kentucky Children's Hospital, University of Kentucky College of Medicine, Lexington, KY, USA 
Keywords Learning outcomes - General education - Undergraduate study· Generic skill · Chinese

\section{Introduction}

In a global economy, a quality higher education adds value not only to individuals but also to the society (McMahon 2009). What students learn and gain from university will determine their opportunities to survive and thrive in an increasingly competitive society. In addition to the long-term impacts on university graduates, the quality of higher education also has a profound impact on a nation's place in the world. In Hong Kong, the University Grants Committee (UGC) (2004) stated that realization of Hong Kong's ambition "to be Asia's world city" is "only possible if it is based upon the platform of a very strong education and higher education sector" (p. 3). It is this profound value of higher education makes developing higher education one of many countries' top priorities. Take the United States as an example, student enrollment at higher education increased from 15.9 million to 21.0 million from 2001 to 2011 (Snyder and Dillow 2013), and President Obama (2009) advocated that the United States should have the highest proportion of college graduates by 2020 . The importance of higher education has been increasingly recognized in Hong Kong as well. The number of university students enrolled in eight UGC-funded institutions increased by $67.2 \%$ between 2004 and 2014, from 47,489 to 79,369, and the total expenditure of eight institutions increased even greater by $73.8 \%$ during the same time from HK\$17,614 million to HK\$30,610 million (University Grants Committee 2016).

The rapid development of higher education and the corresponding increase in resources being invested have raised widespread public concerns about accountability in higher education (Ikenberry and Kuh 2015). The drive for more accountability leads to increased attention on assessment of student learning outcomes (SLOs). Primarily, defining learning outcomes becomes a common practice in universities. According to Kuh et al.'s (2014) report, in 2013, approximately $84 \%$ of colleges and universities in the United States have clearly stated learning outcomes on different levels including lecture, subject and program levels. Besides, SLOs assessment activities increased significantly than a few years ago (Kuh et al. 2014). Consistent with the multi-level feature of SLOs, assessment can be carried out on different levels. For example, it is very common for teachers and researchers to plan SLOs for individual lessons and/or courses and carry out corresponding assessment activities (e.g., quiz or writing assignment). Besides, assessment can be focused on "program learning outcomes", which indicate gains of completing the program (Kennedy 2007).

Program-level SLOs assessment usually adopts a value-added model to examine students' gains in such aspects as knowledg, skills, and habits of mind as a result of their higher education career (Roohr et al. 2016). In this field, most research used a cross-sectional design that measures and compares the learning outcome of two different student cohorts (i.e., freshmen and senior students) (Klein et al. 2009; Liu 2011b; Steedle 2012). In these studies, after controlling for the effects of students' performance before attending university, differences between the two cohorts in learning outcome were regarded as students' gains in university. However, cross-sectional data have limitations. For example, findings can be unreliable if the two cohorts have 
significant differences with respect to their demographic characteristics (Liu 2011a). Thus, many researchers advocated for using longitudinal designs which involve comparing SLOs over time for the same student sample (Roohr et al. 2016). However, only few studies used longitudinal designs for SLOs assessment in higher education (Roohr et al. 2016; Zlatkin-Troitschanskaia et al. 2015), mainly due to the expensive cost and time consuming process.

Among extant longitudinal studies, based on a large sample of students in USA, Arum and Roksa (2011) reported that students made limited improvements on critical thinking, writing, and reasoning as measured by Collegiate Learning Assessment (CLA) after three semesters' study in university. It was further revealed that for the same sample, students' CLA scores increased significantly after seven semesters' learning (Arum and Roksa 2014), suggesting that students tend to gain more at a later rather than an early stage of their university study. Similar results were presented in other studies (Blaich and Wise 2011; Roohr et al. 2016). In Europe, a few large-scale longitudinal SLOs assessment projects have also been carried out since the last decade (Zlatkin-Troitschanskaia et al. 2015). While these studies have provided some evidence for higher education accountability in respective countries, they primarily focused on students' intellectual development (e.g., critical thinking), while devoted less attention to their holistic development that encompasses both intellectual and interpersonal competencies (e.g., leadership skills).

SLOs of general education or liberal arts curricula have been well recognized as comprehensive program-level SLOs that represent the integration but not a simple compilation of all SLOs of general education subjects (King et al. 2007). Furthermore, different categorization methods have been adopted to conceptualize SLOs of general education. To illustrate, The Association of American Colleges and Universities (2005) categorized SLOs of liberal education into three clusters: "knowledge of human culture and the natural world", "intellectual and practical skills", and "individual and social responsibility” (p. 6). King et al.'s (2007) seven-dimensional model appeared to be more comprehensive and encompassing personal and social dimensions of general education learning, with the seven dimensions being: "integration of learning", "inclination to inquire and lifelong learning", "effective reasoning and problem solving", "moral character", "intercultural effectiveness", "leadership", and "wellbeing" (p. 5). Scholars stated that these categories not only "reflect distinct attributes" but also "represent an integrated, holistic approach" to index general education SLOs (King et al. 2007, p. 4). This model was widely adpoted to guide SLOs measurement in research on the benefits brought by general education to university students (Kilgo et al. 2014; Pascarella et al. 2013; Seifert et al. 2014). However, most studies focused only on one or two dimensions. Systematic investigation on general education SLOs in multiple dimensions, such as both cognitive (e.g., critical thinking) and social dimensions (e.g., leadership), remains scarce.

Besides, most studies were conducted in Western countries, and longitudinal SLOs assessment in the Chinese context is scanty. For example, in a study reviewing research about student competence assessment in higher education, no research conducted in the Chinese context was mentioned (Zlatkin-Troitschanskaia et al. 2015). With particular reference to Hong Kong, higher education sector, general education in particular, has experienced major reform and development during past few years (Jaffee 2012, 2013). Specifically, the eight public universities in Hong Kong formally changed their 3-year 
undergraduate education to 4-year ones in 2012-2013 academic year. The additional one year allows these universities to implement their own general education curriculum, which is expected to promote students' all-round development to underpin Hong Kong's competitiveness in a global market era (Freake 2013). With such an emphasis on students' holistic development, it is especially relevant to assess general education SLOs as a timely action to demonstrate the accountability of higher education that incorporates general education. To this end, the present study aimed to investigate students' general education learning outcomes in one Hong Kong University using longitudinal study design.

Another research gap in the extant literature is that potential moderating effects of students' demographic characteristics on their general education learning outcomes were seldom examined. In the field of psychological research, ample studies have revealed that students' background characteristics, such as gender, family economic status, and parental relationship, significantly influenced students' development. In particular, although some studies demonstrated that boys outperformed girls in science subjects such as mathematics (Else-Quest et al. 2010), a recent meta-analytical review reported a stable female advantage in intellectual achievement in all kinds of subjects across educational contexts, including university (Voyer and Voyer 2014). Findings in SLOs assessment studies were mixed. For example, Roohr et al. (2016) examined whether gender predicted university students' learning gains in critical thinking, reading, writing, and mathematics, but they did not find any significant gender effect. However, less effort has been devoted to investigate whether and how gender would affect student achievement in other dimensions.

Family factors such as economic status and parental involvement were also significantly associated with university students' academic performance (Islam 2014). Related studies suggested that these family background factors may exert even greater influence on students' development on social dimensions. For instance, a harsh family environment (e.g., poor, non-intact family structure) was found to significantly raise the prevalence of depression symptoms (Frasquilho et al. 2016) while reduce well-being (Yu et al. 2015) among university students. Noteworthy, recent studies based on largescale longitudinal data revealed that intact family structure and better economic condition would promote adolescents' health development in multiple dimensions and prevent them from involving problem behavior, both concurrently and longitudinally (Shek and Leung 2016; Shek and Lin 2014, 2016).

Despite above findings which suggest the moderating effects of social-demographic characteristics on students' development, very few studies have related such correlates to university students' general education learning outcomes. To address this research gap, the present study also explored whether students' general education learning outcomes were significantly correlated with three socio-demographic factors, including gender, family intactness, and family economic condition.

\section{The Present Study}

To fill the above-mentioned research gaps, the present study attempted to provide a systematic examination of students' general education learning outcomes based on a four-year longitudinal design in Hong Kong. As different universities in Hong Kong 
have designed different SLOs for their respective general education curriculums since education reform, we examined university students' general education learning outcomes with regard to one public university (i.e., A university), in which a general education curriculum entitled "General University Requirement" has been implemented as a fundamental unit of the 4-year undergraduate curriculum.

Under the "General University Requirement", multiple components were offered throughout years of university study. In each year, students mainly studied particular components with some flexibility. For example, students were required to study Freshmen Seminar in Year 1 and Service Learning in Year 2, and they were advised to complete the components of Leadership and Intrapersonal Development, Cluster Areas Requirements, Healthy Lifestyle, Language and Communication Requirements in their first three years of university study. Noteworthy, these components covered a wide range of subjects, which were well-designed to cultivate comprehensive competencies in students, such as critical thinking, problem solving, and ethical leadership (Shek et al. 2014b), which were conceptually similar to the multi-dimensional general education SLOs in King et al.'s (2007) model.

Therefore, King et al.'s (2007) seven-dimensional model was utilized to guide measurement of multiple general education learning outcomes. Among the seven dimensions, we measured four that can cover both cognitive ("effective reasoning and problem solving", and "integration of learning") and social aspects (i.e., "leadership" and "moral character") of student development. The attributes measured by these four dimensions are largely aligned with the intended learning outcomes of general education in A university (Shek et al. 2014b). These attributes were measured and compared across four years.

Based on previous findings showing benefits of university study, especially the general education learning (Kilgo et al. 2014, 2015), it was hypothesized that students gained improvement regarding the general education learning outcomes during the four years. Regarding socio-demographic factors that might affect student development, the focus of the present study was on gender and two family background factors, i.e., economic disadvantage and family intactness. Based on aforementioned literature review (Shek and Lin 2014; Voyer and Voyer 2014), we also expected significant moderating effects of the three socio-demographic factors.

\section{Methods}

\section{Participants and Procedures}

A randomly selected cohort of students enrolled in the 4-year undergraduate curriculum of the A University was followed up since they started their university study in 20122013 academic year. Before the baseline data collection (i.e., Wave 1), 650 first-year students were randomly selected and invited via email or phone calls to participate in a longitudinal study with yearly online surveys. Students were informed that the study aims to investigate student development in university. They were also well informed that any information collected from them would be strictly kept confidential and only used for research purpose. A written informed consent was obtained from those students agreeing to join the study. 
The Wave 1 data collection was carried out in November 2012 via an online survey, with 543 out of 650 invited students completing the survey, suggesting a response rate of $83.54 \%$. The online survey comprised measures of participants' demographic information (e.g., gender, age, and place of birth), family background (e.g., economic disadvantage and family intactness), and other variables. SLOs measurement was one part of the online survey.

After baseline data collection, those 543 participants were followed up each year in November and another three waves of data have been collected till 2015 (i.e., Wave 2: 2013-2014 year; Wave 3: 2014-2015 year; Wave 4: 2015-2016 year). In each wave of data collection, participants completed the same online survey, which included measures of general education learning outcomes.

In total, 434 participants $\left(M_{\text {age }}=18.13, S D_{\text {age }}=.54\right.$ at Wave 1$)$ were successfully matched across four waves, suggesting a low average attrition rate of $5.02 \%$ during four years. Among the 434 participants, 38.71\% $(n=168)$ were male and $61.29 \%(n=266)$ were female. All these participants were Asian, among whom 314 (72.35\%) were born in Hong Kong, 106 (24.42\%) in mainland China, while the remaining 14 (3.23\%) were born in other places.

No significant differences between the matched sample $(n=434)$ and those dropouts $(n=109)$ were found regarding demographic information (i.e., age, ethnicity, gender composition, place of birth), family background, and baseline scores of general education learning outcomes.

\section{Student Learning Outcomes (SLOs) Measures}

As mentioned before, four out of seven dimensions in King et al.'s (2007) model of general education SLOs were measured, including cognitive (i.e., "effective reasoning and problem solving", and "integration of learning") and social aspects (i.e., "leadership" and "moral character") of student development. Scales that tap the four dimensions were developed through selecting items of existing measures and drafting a few new items by the research team. Besides, it was noted that some present general education learning outcome measures overlapped with well-being indicators in a recent study (Shek et al. 2016c). For example, moral competence was used as one indicator of the developmental assets and reflective and integrative learning as one measure of university engagement. To have a comprehensive framework of general education learning outcomes, the present study still included these two measures. However, students' changes on the two overlapped indicators would not be reported to avoid reporting findings that have been covered in previous study. Nevertheless, relationships between these two indicators and social-demographic factors were revealed in the current study.

\section{Dimension 1-Effective Reasoning and Problem Solving}

According to the definition of effective reasoning and problem solving (King et al. 2007), this dimension represents students' cognitive capacity of analyzing, critical thinking, making judgments, and taking actions. Based on this conceptual understanding, we operationalized this dimension using three indicators: problem solving, critical thinking, and cognitive-behavioral competence. The first two indicators were measured 
with two self-reported scales we developed for the present study. Each scale has three items and a 6-point Likert rating scale was adopted for all items with a higher score representing a higher capacity. Across four waves, these two scales showed acceptable reliability, with Cronbach's $\alpha$ ranging from .66 to .85. Other details including sample items are depicted in Table 1.

The third indicator, cognitive-behavioral competence, concerned students' skills in solving problems by thinking independently and taking effective actions in Chinese Positive Youth Development Scale (CPYDS) (Shek and Ma 2010; Shek et al. 2007). The CPYDS was developed by Shek et al. (2007), which had 15 subscales corresponding to 15 constructs of positive youth development attributes proposed by Catalano et al. (2002). This instrument has shown sound validity and reliability in measuring Chinese young people's positive attributes in previous studies (Shek and Ma 2010). In the CPYDS, cognitive-behavioral competence was a composite score (i.e., higher-order factor) calculated from three subscales: cognitive competence, behavioral competence, and self-determination. The eight items of cognitive-behavioral competence were reported using a 6-point scale with a higher score representing a better outcome. In the present study, this composite measure demonstrated good reliability across four waves (see Table 1).

\section{Dimension 2-Integration of Learning}

This dimension refers to the "ability to connect information from disparate contexts and perspectives" (King et al. 2007, p. 5), such as the ability to connect learning in school with societal issues, knowledge or idea learned in the present with prior experience, and one field of learning with another. These abilities could be largely, if not fully, covered by one subscale entitled "Reflective and Integrative Learning" in newly updated National Survey of Student Engagement (2015), which consisted of 47 items in total. These 47 items were further divided into 10 subscales to assess student engagement in high levels of learning and development, and have been widely used in many countries, including China (Kuh 2001; Shi and Wen 2012). The "Reflective and Integrative Learning" subscale used in the present study consisted of 7 items assessing the extent to which students integrate their learning experiences in different courses, and connect school learning to previous or concurrent real life experiences. In the present study, a 4-point Likert scale was used and good reliability was observed (see Table 1).

\section{Dimension 3-Leadership}

The leadership dimension of King et al.'s (2007) model included core values in three realms, including individual, group and community, which were conceptually in line with the philosophy system of a service leadership theory. This leadership theory was proposed and adopted to guide leadership education in contemporary Hong Kong to meet the growing needs of the predominant service sectors (Shek et al. 2013). The service leadership theory believes that "leadership is a service aimed at ethically satisfying the needs of self, others, groups, communities, systems, and environments" and "service includes self-serving efforts aimed at ethically improving one's competencies, abilities, and willingness to help satisfy the needs of others" (Shek et al. 2013, p. 354). 


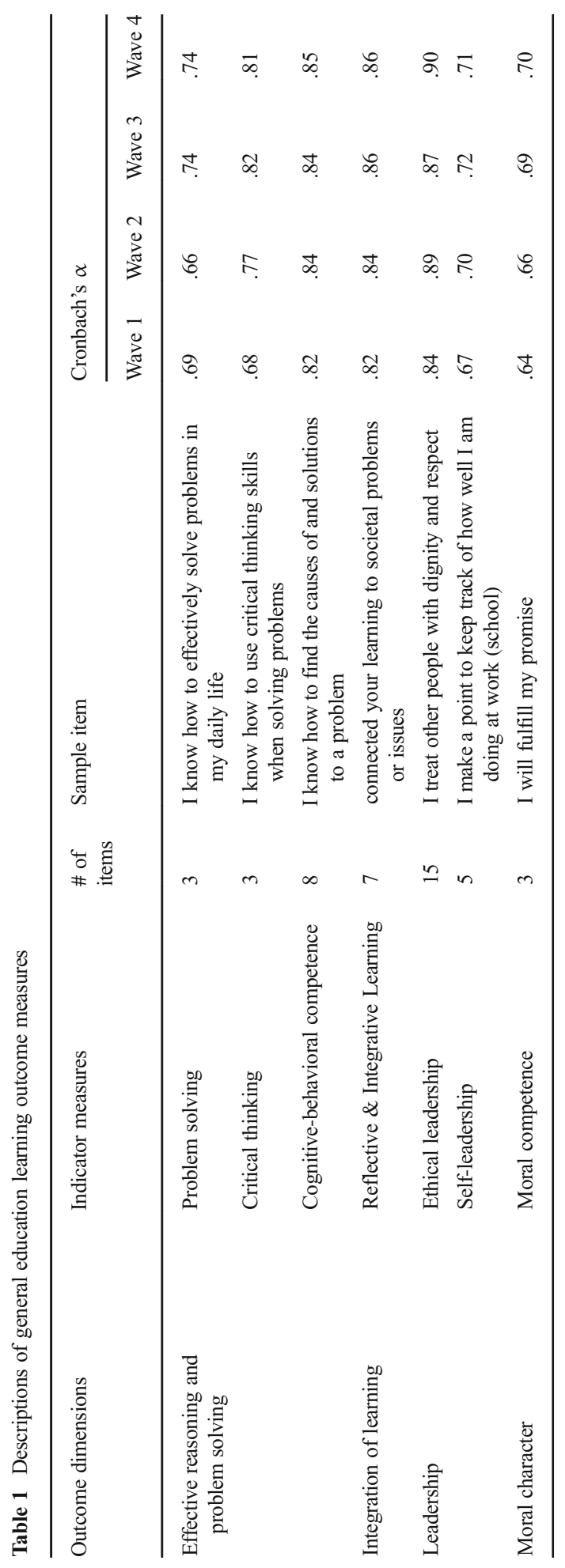


Basically, the ethical requirement and self-leadership, which refers to one's ability to manage oneself and improve one's full range of competencies, are two most important qualities highlighted by service leadership theory. Thus, ethical leadership and selfleadership scales were developed to evaluate service leadership education and the two scales showed good reliability in previous studies (Shek et al. 2014a, 2017). Ethical leadership scale consisted of 15 items using a 6-point Likert scale whereas selfleadership scale included 5 items adopting a 5-point Likert rating scale. In the present study, these two scales were utilized to index the leadership dimension of the general education learning outcomes. The two scales showed good reliability (see Table 1).

\section{Dimension 4-Moral Character}

Moral competence, which refers to the capacity to differentiate right and wrong, perform ethical behaviors, and respect for social laws, rules, and justice (Ma 2012), was used to index the dimension of moral character. In the present study, we used the moral competence subscale of abovementioned CPYDS, which had 3 items using a 6point rating scale. The moral competence measure showed acceptable reliability in the present study (see Table 1).

\section{Family Background Measures}

\section{Family Intactness}

Similar to previous research (Shek and Lin 2016), family intactness was evaluated using marital status of participants' parents. A total of 370 (85.25\%) participants who reported that their parents were in the first marriage were categorized into the group with intact family, and 64 (14.75\%) participants whose parents were divorced, separated or in their second marriage were categorized into the non-intact family group.

\section{Family Economic Condition}

Economic status of each participant was determined by whether his/her family received Government welfare in Hong Kong (i.e., Comprehensive Social Security Assistance Scheme, CSSA) before entering university. In total, 38 (8.80\%) participants reported receiving CSSA, so these participants were categorized as poor. Other $386(88.9 \%)$ participants whose family did not receive CSSA were regarded as non-poor.

\section{Data Analysis}

To compare general education learning outcomes across years, we performed a repeated-measures multivariate analysis of variance (MANOVA) with univariate tests, using the seven indicators of learning outcomes as dependent variables (DVs), time operationalized as four waves as the within-participant independent variable (IV). Results of two measures (i.e., "reflective and integrative learning" and "moral competence") were reported elsewhere (Shek et al. 2016c). After this step, using the same DVs and within-participant IV, we further performed three separate repeated measures MANOVAs, with each using one of the three demographic variables (gender, 
family intactness, and economic condition) as the between-participant IV, to explore the potential moderating effects of the respective demographic variable.

\section{Results}

\section{General Education Learning Outcomes in Four Waves}

Repeated measures MANOVA revealed a significant main effect of time (Wilks' $\left.\lambda=.74, F(21,3713)=19.43, p<.001, \eta_{p}^{2}=.09\right)$, suggesting significant differences of participants' general education learning outcomes across four waves. Results of further univariate tests and pair-wise comparisons using Bonferroni tests are presented in Table 2.

\section{Effective Reasoning and Problem Solving}

Three indicators including problem solving, critical thinking, and cognitive-behavioral competence were used to index learning outcomes in this dimension. Results of univariate tests showed that there were significant differences in participants' scores of all three indicators across four waves with partial effective sizes ranging from .02 to .07 (see Table 2). Post-hoc pairwise comparisons further revealed a U-shaped trajectory of students' development in effective reasoning and problem solving dimension. Specifically, students' scores at Wave 2 tended to be lower than that at Wave 1 in the three indicators. However, such a tendency did not reach a significant level for problem solving and critical thinking. After Wave 2, students' performance rebounded steadily and they had highest scores at Wave 4 regarding problem solving and critical thinking.

\section{Leadership}

Leadership dimension was accounted by ethical leadership and self-leadership. As shown in Table 2, students also showed significant changes over time in ethical

Table 2 Comparisons of students' general education learning outcomes across four waves $(n=434)$

\begin{tabular}{|c|c|c|c|c|c|c|c|c|c|c|c|}
\hline \multirow{2}{*}{$\begin{array}{l}\text { Indicator } \\
\text { measures }\end{array}$} & \multicolumn{2}{|c|}{ Wave 1} & \multicolumn{2}{|c|}{ Wave 2} & \multicolumn{2}{|c|}{ Wave 3} & \multicolumn{2}{|c|}{ Wave 4} & \multicolumn{3}{|c|}{ Univariate tests of repeated measures MANOVA } \\
\hline & $M$ & $S D$ & $M$ & $S D$ & $M$ & $S D$ & $M$ & $S D$ & $\mathrm{~F}$ & $\eta_{p}^{2}$ & Pairwise comparisons \\
\hline PS & 4.28 & .71 & 4.25 & .67 & 4.47 & .65 & 4.52 & .63 & $34.05^{* * *}$ & .07 & $\mathrm{~W} 4 \& \mathrm{~W} 3>\mathrm{W} 2 \& \mathrm{~W} 1$ \\
\hline $\mathrm{CT}$ & 4.64 & .63 & 4.58 & .67 & 4.66 & .70 & 4.74 & 67 & $7.97^{* * * *}$ & .02 & W4 > W2 \& W1 \\
\hline $\mathrm{CBC}$ & 4.53 & .55 & 4.46 & .59 & 4.54 & .59 & 4.58 & .60 & $6.72^{* * *}$ & .02 & $\mathrm{~W} 4 \& \mathrm{~W} 3>\mathrm{W} 2 ; \mathrm{W} 1>\mathrm{W} 2$ \\
\hline EL & 4.67 & .45 & 4.57 & .53 & 4.62 & .49 & 4.65 & .53 & $6.70^{* * *}$ & .02 & $\mathrm{~W} 4 \& \mathrm{~W} 1>\mathrm{W} 2$ \\
\hline SL & 3.83 & .55 & 3.78 & .57 & 3.85 & .58 & 3.88 & .56 & $3.67^{*}$ & .01 & $\mathrm{~W} 4>\mathrm{W} 2$ \\
\hline
\end{tabular}

Results for moral competence and reflective \& integrative learning are not included

PS Problem Solving, CT Critical Thinking, $C B C$ Cognitive-Behavioral Competence, EL Ethical Leadership, SL Self-Leadership

$* p<.05 ; * * p<.01 ; * * * p<.001$ 
leadership $\left(F(3,1299)=6.70, p<.001, \eta_{p}^{2}=.02\right)$ and self- leadership $(F(3,1299)=$ $\left.3.67, p<.05, \eta_{p}^{2}=.01\right)$. Besides, a U-shaped trajectory was also observed regarding students' score in these two leadership indicators, but only the decrement in ethical leadership from Wave 1 to Wave 2 was significant. After Wave 2, students' performance in leadership dimension rebounded continuously, with scores at Wave 4 significantly higher than that at Wave 2 .

\section{Moderating Effects of Gender and Family Background}

Gender showed a significant interaction with time on indicators of general education learning outcomes (Wilks' $\lambda=.97, F(21,3704)=1.61, p<.05, \eta_{p}^{2}=.01$ ). Further analyses revealed that male and female students had significant different change patterns in three indicators: problem solving $\left(F(3,1296)=3.37, p=.02, \eta_{p}^{2}=.008\right)$, cognitive-behavioral competence $\left(F(3,1296)=2.93, p=.03, \eta_{p}^{2}=.007\right)$, and reflective and integrative learning $\left(F(3,1296)=2.65, p=.047, \eta_{p}^{2}=.006\right)$.

To account for the moderating effects of gender, we then conducted repeated measures MANOVAs for the three indicators (i.e., problem solving, cognitivebehavioral competence, and reflective and integrative learning) separately for male and female samples. Significant differences in the three indicators over time were found for male students (Wilks' $\lambda=.80, F(9,1214)=13.05, p<.001, \eta_{p}^{2}=.07$ ) and female students (Wilks' $\left.\lambda=.70, F(9,1930)=33.37, p<.001, \eta_{p}^{2}=.11\right)$. Results are demonstrated in Table 3.

As shown in Table 3, although both female and male students changed significantly in these three indicators over time, their change patterns demonstrated some differences. For problem solving (see Fig. 1) and cognitive-behavioral competence (see Fig. 2), male and female students differed mainly in two ways. First, male students were more likely to experience a decrement from Wave 1 to Wave 2 than did female students. Second, male students seemed to have a steadier growth than did female students from the second year to the fourth year of university study. For reflective and integrative learning (see Fig. 3), female and male students' change patterns over time

Table 3 Comparisons of students' learning outcomes across four waves by gender (Female: $n=266$; Male: $n=168$ )

\begin{tabular}{|c|c|c|c|c|c|c|c|c|c|c|c|c|}
\hline \multirow[t]{2}{*}{$\begin{array}{l}\text { Indicator } \\
\text { measures }\end{array}$} & \multirow[t]{2}{*}{ Gender } & \multicolumn{2}{|c|}{ Wave 1} & \multicolumn{2}{|c|}{ Wave 2} & \multicolumn{2}{|c|}{ Wave 3} & \multicolumn{2}{|c|}{ Wave 4} & \multicolumn{3}{|c|}{$\begin{array}{l}\text { Univariate tests of repeated measures } \\
\text { MANOVA }\end{array}$} \\
\hline & & $M$ & $S D$ & $M$ & $S D$ & $M$ & $S D$ & $M$ & $S D$ & $\mathrm{~F}$ & $\eta_{p}^{2}$ & Pairwise comparisons \\
\hline \multirow[t]{2}{*}{ PS } & Female & 4.22 & .72 & 4.23 & .66 & 4.49 & .63 & 4.50 & .65 & $29.07^{* * * *}$ & .10 & $\mathrm{~W} 4$ \& W3 > W2 \& W1 \\
\hline & Male & 4.37 & .69 & 4.28 & .70 & 4.43 & .68 & 4.55 & .60 & $9.13^{* * *}$ & .05 & $\mathrm{~W} 4>\mathrm{W} 3>\mathrm{W} 2 ; \mathrm{W} 4>\mathrm{W} 1$ \\
\hline \multirow[t]{2}{*}{$\mathrm{CBC}$} & Female & 4.49 & .56 & 4.47 & .56 & 4.55 & .56 & 4.54 & .60 & $2.65^{*}$ & .01 & $\mathrm{~W} 3>\mathrm{W} 2$ \\
\hline & Male & 4.59 & .54 & 4.45 & .63 & 4.54 & .64 & 4.64 & .59 & $6.20^{* * * *}$ & .04 & $\mathrm{~W} 4 \& \mathrm{~W} 1>\mathrm{W} 2$ \\
\hline \multirow[t]{2}{*}{ RIL } & Female & 2.35 & .47 & 2.25 & .47 & 2.66 & .48 & 2.61 & .49 & $87.03^{* * * *}$ & .25 & $\begin{array}{l}\mathrm{W} 4 \& \mathrm{~W} 3>\mathrm{W} 2 \& \mathrm{~W} 1 \\
\mathrm{~W} 1>\mathrm{W} 2\end{array}$ \\
\hline & Male & 2.33 & .50 & 2.33 & .48 & 2.61 & .55 & 2.65 & .51 & $31.12^{* * * *}$ & .16 & W4 \& W3 > W2 \& W1 \\
\hline
\end{tabular}

PS Problem solving, CBC Cognitive-Behavioral Competence, RIL Reflective \& Integrative Learning $* p<.01 ; * * * p<.001$ 


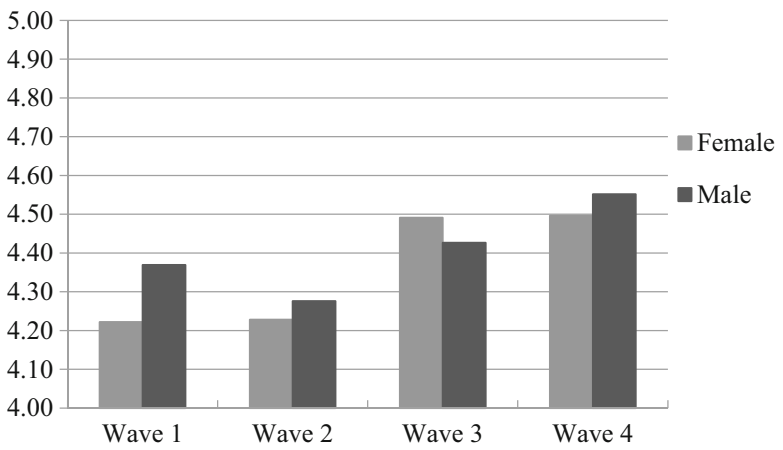

Fig. 1 Students' problem solving across waves by gender

were roughly the same: a U-shaped trajectory with a decrement at Wave 2 and a stable rebound afterward. One exception is that the decrement from Wave 1 to Wave 2 was significant in female students but not in male students. Besides, female students' variations in this indicator over time seemed larger than that of male students as reflected by a larger effect size among female students.

For family intactness and economic disadvantage, no significant interactions with time were found, suggesting that these two factors do not have a significant impact on students' development pattern over time in the four dimensions of general education learning outcomes.

\section{Discussion}

Assessing student learning outcomes (SLOs) after receiving higher education can inform students' achievement, help evaluate the effectiveness and quality of university education, and inform directions of improvement within the institution as well. With the development of higher education systems and calls for accountability, assessment of SLOs on program level has drawn much more attention during past few decades than before (Kuh et al. 2014). To this end, nationwide studies have been conducted in the United States and European countries to measure student learning achievement in

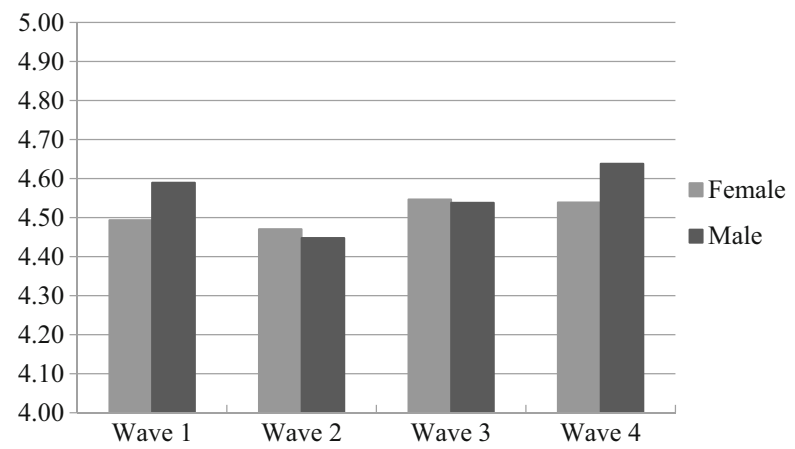

Fig. 2 Students' cognitive-behavioral competence across waves by gender 


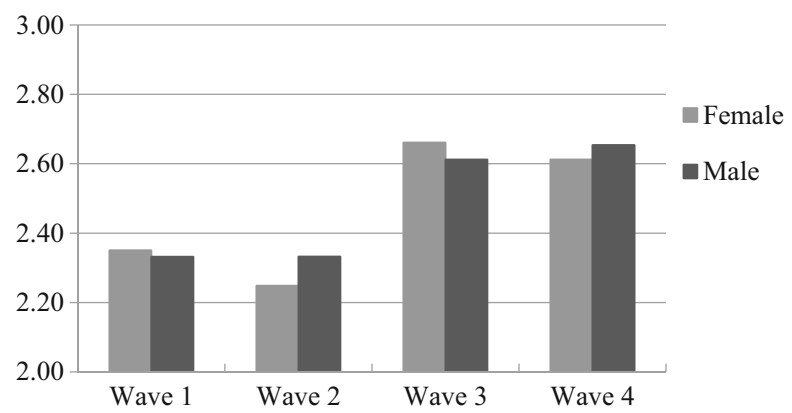

Fig. 3 Students' reflective and integrative learning across waves by gender

colleges and universities (Zlatkin-Troitschanskaia et al. 2015). However, most of these studies focused on students' intellectual development while overlooking achievement in other aspects, such as development of social skills and character. Besides, very few studies have systematically investigated SLOs using a longitudinal design, especially in Chinese contexts. In this situation, the present study represents a pioneer attempt in Hong Kong to longitudinally assess multi-dimensional general education SLOs as representatives of comprehensive college-level SLOs. The study not only contributes to extant literature theoretically by filling the vacancy in conducting college-level SLOs assessment in Hong Kong, but also benefits university policy makers and the general education curriculum designers in Hong Kong by revealing students' change patterns and moderating factors.

Results of the present study revealed that students gained no improvement after the first year of university study. The finding is consistent with previous observations, suggesting that students did not make significant gains in the first year of college (Arum and Roksa 2014; Roohr et al. 2016). As argued by some researchers, this may be due to the fact that students need to spend time in "observing and learning about the college community" (Roohr et al. 2016, p. 11) before they are able to engage in independent and deeper learning, through which improvement in learning outcomes can be better obtained. Also, freshmen need some time to adapt to the new educational demands and social environment in college, which makes their learning in the first few years less effective (Roohr et al. 2016).

Apart from the common challenges that freshmen face, students in the present study may undergo other particular difficulties in the first year of university study. For example, experiential and interactive pedagogy adopted by most general education subjects, which require students' active learning and engagement may put extra pressure on students to adjust to university study (Shek et al. 2014b). This is because Hong Kong students were used to didactic teaching and rote memorization before entering university and may have difficulties and reluctances in shifting to studentcentered and independent, active, and comprehensive learning (Jaffee 2012). This particular challenge could also help to explain why students even showed a significant decrement in some indicators of learning outcomes in their first year of university life.

Nevertheless, students' self-reported performance in learning outcome measures rebounded after the second year of university study and maintained a steady growth in the following years. These results echo previous findings which showed that college students made greater gains from sophomore to senior years (Arum and Roksa 2014; 
Roohr et al. 2016). First of all, students' learning may speed up after they have acclimated to university life and study (Roohr et al. 2016). Moreover, students finally are able to recognize and enjoy the benefits of inspirational teaching and learning pedagogy in most general education subjects, despite difficulties they encountered at the beginning. This assertion is evident by previous findings on how students perceived the general education subjects in Hong Kong - although some students expressed that they felt difficulty in digesting multidisciplinary knowledge and fulfilling educational demands in general education subjects, most students regarded the rich content and active pedagogy in these subjects as helpful and effective in cultivating their all-round competencies (Shek and Law 2014; Shek et al. 2014b). As a result, students' achievement in different dimensions of learning outcomes found in the present study provides evidence for the value of the general education-embeded higher education system, which in general could help promote university students' holistic development.

Consistent with our expectation, gender had a significant moderating effect on students' development regarding three learning outcome indicators (i.e., problem solving, cognitive-behavioral competence, and reflective and integrative learning). Although both male and female students demonstrated a U-shaped trajectory in these indicators, they still differed in some aspects regarding their development pattern. Arguably, gender might play an important role in students' university learning. However, the present finding is kindly inconsistent with some previous findings. For example, in Roohr et al.'s (2016) study, factors including gender, major, and ethnicity did not play a significant role in moderating student gains after attending college. Therefore, further examinations are needed to obtain a conclusive result about the gender difference in achieving general education learning outcomes.

For the two family background factors, i.e., family intactness and economic disadvantage, previous studies have found a significant effect on students' development in attributes like moral competence and social competence during secondary school study (Shek et al. 2016a, b). In contrast, these two factors had no significant influence on university students' growth in the current study. The results suggest that university students may have been mature enough to be less or even not susceptible to the adverse family environment. For example, with expanded social circle, relationship with peers and other adults may play an increasingly important role in university students' life than do their parents. Given that the present findings represent preliminary exploration in Hong Kong, they need to be validated in future and interpreted with cautions.

Apart from theoretical implications, the present four-year longitudinal findings on SLOs also have practical implications. As we mentioned before, during the first year of university life and general education study, students need to deal with various challenges and experience great pressure, all of which may have adverse impacts on achieving intended university learning outcomes. Therefore, to help students better adapt to university life and learn general education subjects more effectively, it would be necessary to provide more support for students during first year through offering specific programs, courses, or consultation sessions. For example, freshmen seminars could be conducted throughout the first year to guide the students to make proper psychological adjustment and help them realize their strength in different areas of university study. Besides, giving freshmen time and opportunities to adapt to the teaching and learning pedagogy used in the general education subjects by delivering less demanding courses first would help reduce students' pressure. The moderating 
effect of gender observed in the present study is also instructive for educational practices in university. For example, when providing help or consultation, educators should pay more attention to male students in certain areas (e.g., enhancing problem solving skills in the first-year transition) while caring more about female students in other areas (e.g., promoting integrative learning in the first-year transition). Teachers should also be alert to the dip in well-being and adjustment in students during the first year of their study.

Despite the theoretical and practical value, the present study still has several limitations. The first limitation is that we only collected data from one university in Hong Kong due to difficulties and challenges in following up students over multiple years. Findings based on data from multiple institutions could be generalized to a broader population with more confidence. Furthermore, comparisons of SLOs across universities may also shed light on whether and how differences between universities affect students' development. As a result, researchers need to conduct longitudinal studies based on different universities in Hong Kong and other Chinese communities (e.g., mainland China) or even abroad.

Second, although longitudinal designs are recommended to reliably examine student gains in university (Porter 2012), it costs much more time and resources than do crosssectional studies. Future research could compare results generated from these two research designs to provide empirical support for using cross-sectional designs when limited resources are available, as long as cross-sectional designs can produce similar results as longitudinal designs.

The third limitation concerns the self-report measures used in the present study. Although researchers have found that university students are able to accurately evaluate their own ability at one specific time point (Bowman and Green 2013), it is better to use standardized tests to objectively assess students' ability as endorsed by other researchers (Zlatkin-Troitschanskaia et al. 2015). Future research could benefit from comparing findings obtained from self-report measures and standardized tests.

Fourth, without a control group, it is theoretically possible that student changes in indicators under investigation simply result from developmental maturation. It is noteworthy that no previous studies have assumed that university students necessarily make gains in those general education learning outcomes (Nelson et al. 2009; Roohr et al. 2016). Besides, maturation could not explain students' change after the first year of university life. Therefore, it is very much unlikely that the present findings are entirely attributed to maturation. Another issue is that experience other than general education-embedded higher education study (e.g. internship experience) during the present study period could also lead to students' changes. It is difficult, if not impossible, to separate specific effects between university study and other learning experience. However, university courses, especially the general education subjects have a specific focus on learning outcomes under investigation. Therefore, we still tend to think that general education-incorporated higher education learning at least partially contributes to students' development found in present study. Despite these limitations, this study is a pioneer one in different Chinese contexts.

Acknowledgments This paper was financially supported by The Hong Kong Polytechnic University under Learning and Teaching Development Funding. The authors declare that there is no conflict of interest with any financial organizations regarding the materials reported in this manuscript. 
Open Access This article is distributed under the terms of the Creative Commons Attribution 4.0 International License (http://creativecommons.org/licenses/by/4.0/), which permits unrestricted use, distribution, and reproduction in any medium, provided you give appropriate credit to the original author(s) and the source, provide a link to the Creative Commons license, and indicate if changes were made.

\section{References}

Arum, R., \& Roksa, J. (2011). Academically adrift: Limited learning on college campuses. Chicago: University of Chicago Press.

Arum, R., \& Roksa, J. (2014). Aspiring adults adrift: Tentative transitions of college graduates. Chicago: University of Chicago Press.

Association of American Colleges and Universities. (2005). Liberal education outcomes: A preliminary report on student achievement in college. Washington, DC: AAC\&U.

Blaich, C.F., \& Wise, K.S. (2011). From gathering to using assessment results: Lessons from the Wabash national study (NILOA Occasional Paper No. 8). Urbana, IL: University of Illinois and Indiana University, National Institute for Learning Outcomes Assessment.

Bowman, N. A., \& Green, B. (2013). Understanding and addressing the challenges of assessing college student growth in student affairs. Research \& Practice in Assessment, 8, 5-14.

Catalano, R. F., Berglund, M. L., Ryan, J. A., Lonczak, H. S., \& Hawkins, J. D. (2002). Positive youth development in the United States: research findings on evaluations of positive youth development programs. Prevention \& Treatment, 5, Article 15. https://doi.org/10.1037/1522-3736.5.1.515a.

Else-Quest, N. M., Hyde, J. S., \& Linn, M. C. (2010). Cross-national patterns of gender differences in mathematics: a meta-analysis. Psychological Bulletin, 136(1), 103-127. https://doi.org/10.1037 /a0018053.

Frasquilho, D., de Matos, M. G., Gaspar, T., \& de Almeida, J. C. (2016). Young people's well-being and the economic crisis: how does parental unemployment and family wealth affect the downturn experience? Children and Youth Services Review, 69, 219-222.

Freake, H. (2013). Curricular designs for general education at the UGC-supported universities in Hong Kong. In J. Xing, P.-S. Ng, \& C. Cheng (Eds.), General education and the development of global citizenship in Hong Kong, Taiwan and mainland China (pp. 105-120). New York: Routledge.

Ikenberry, S. O., \& Kuh, G. D. (2015). From compliance to ownership: Why and how colleges and universities assess student learning. In G. D. Kuh, S. O. Ikenberry, N. A. Jankowski, T. R. Cain, P. Hutchings, \& J. Kinzie (Eds.), Using evidence of student learning to improve higher education (pp. 1-23). San Francisco: Jossey-Bass.

Islam, M. M. (2014). Factors influencing the academic performance of undergraduate students in Sultan Qaboos University in Oman. Journal of Emerging Trends in Educational Research and Policy Studies, 5(4), 396-404.

Jaffee, D. (2012). The general education initiative in Hong Kong: organized contradictions and emerging tensions. Higher Education, 64(2), 193-206. https://doi.org/10.1007/s10734-011-9487-y.

Jaffee, D. (2013). Building general education with Hong Kong characteristics. International Education, 42(2), 41-59.

Kennedy, D. (2007). Writing and using learning outcomes: a practical guide. Cork, Munster: University College Cork.

Kilgo, C. A., Pasquesi, K., Sheets, J. K. E., \& Pascarella, E. T. (2014). The estimated effects of participation in service-learning on liberal arts outcomes. The International Journal of Research on Service-Learning and Community Engagement, 2(1), 18-31.

Kilgo, C. A., Sheets, J. K. E., \& Pascarella, E. T. (2015). The link between high-impact practices and student learning: some longitudinal evidence. Higher Education, 69(4), 509-525. https://doi.org/10.1007/s10734014-9788-z.

King, P. M., Brown, M. K., Lindsay, N. K., \& Vanhecke, J. R. (2007). Liberal arts student learning outcomes: an integrated approach. About Campus, 12(4), 2-9. https://doi.org/10.1002/abc.222.

Klein, S. C., Liu, O. L. E., Sconing, J. A., Bolus, R. C., Bridgeman, B. E., Kugelmass, H. C., et al. (2009). Test Validity Study (TVS) report. New York: Collegiate Learning Assessment.

Kuh, G. D. (2001). The National Survey of Student Engagement: Conceptual framework and overview of psychometric properties. http://nsse.iub.edu/pdf/psychometric_framework_2002.pdf. Accessed 15 Feb 2017. 
Kuh, G. D., Jankowski, N., Ikenberry, S. O., \& Kinzie, J. (2014). Knowing what students know and can do: The current state of student learning outcomes assessment at U.S. colleges and universities. Champaign: National Institute for Learning Outcomes Assessment.

Liu, O. L. (2011a). Outcomes assessment in higher education: challenges and future research in the context of voluntary system of accountability. Educational Measurement: Issues and Practice, 30(3), 2-9. https://doi.org/10.1111/j.1745-3992.2011.00206.

Liu, O. L. (2011b). Value-added assessment in higher education: a comparison of two methods. Higher Education, 61(4), 445-461. https://doi.org/10.1007/s10734-010-9340-8.

Ma, H. K. (2012). Moral competence as a positive youth development construct: a conceptual review. The Scientific World Journal, 2012, Article ID 590163. https://doi.org/10.1100/2012/590163.

McMahon, W. W. (2009). Higher learning, greater good: The private and social benefits of higher education. Baltimore: The Johns Hopkins University Press.

National Survey of Student Engagement (2015). Engagement indicators and high-impact practices. http://nsse. indiana.edu/pdf/EIs_and_HIPs_2015.pdf. Accessed 15 Feb 2017.

Nelson, K. J., Duncan, M. E., \& Clarke, J. A. (2009). Student success: the identification and support of first year university students at risk of attrition. Studies in Learning, Evaluation, Innovation and Development, $6(1), 1-15$.

Obama, B. (2009). President Obama's Address to Congress. http://www.nytimes.com/2009/02/24 /us/politics/24obama-text.html?_r=2. Accessed 15 Feb 2017.

Pascarella, E. T., Wang, J.-S., Trolian, T. L., \& Blaich, C. (2013). How the instructional and learning environments of liberal arts colleges enhance cognitive development. Higher Education, 66(5), 569583. https://doi.org/10.1007/s10734-013-9622-z.

Porter, S. R. (2012). Using student learning as a measure of quality in higher education. http://www. hcmstrategists.com/contextforsuccess/papers/PORTER_PAPER.pdf. Accessed 15 Feb 2017.

Roohr, K. C., Liu, H., \& Liu, O. L. (2016). Investigating student learning gains in college: a longitudinal study. Studies in Higher Education. https://doi.org/10.1080/03075079.2016.1143925.

Seifert, T. A., Gillig, B., Hanson, J. M., Pascarella, E. T., \& Blaich, C. F. (2014). The conditional nature of high impact/good practices on student learning outcomes. Journal of Higher Education, 85(4), 531-564. https://doi.org/10.1353/jhe.2014.0019.

Shek, D. T. L., \& Law, M. Y. M. (2014). Evaluation of a subject on leadership and intrapersonal development: views of the students based on qualitative evaluation. International Journal on Disability and Human Development, 13(4), 435-441. https://doi.org/10.1515/ijdhd-2014-0339.

Shek, D. T. L., \& Leung, J. T. Y. (2016). Socio-demographic and family determinants of emotional competence of high school students in Hong Kong: a 6-year longitudinal study. International Journal on Disability and Human Development, 15(4), 397-408. https://doi.org/10.1515/ijdhd-2017-5007.

Shek, D. T. L., \& Lin, L. (2014). Personal well-being and family quality of life of early adolescents in Hong Kong: do economic disadvantage and time matter? Social Indicators Research, 117(3), 795-809. https://doi.org/10.1007/s11205-013-0399-3.

Shek, D. T. L., \& Lin, L. (2016). What predicts adolescent delinquent behavior in Hong Kong? A longitudinal study of personal and family factors. Social Indicators Research, 129(3), 1291-1318. https://oi. org/10.1007/s11205-015-1170-8.

Shek, D. T. L., \& Ma, C. M. S. (2010). Dimensionality of the Chinese Positive Youth Development Scale: confirmatory factor analyses. Social Indicators Research, 98(1), 41-59. https://doi.org/10.1007/s11205009-9515-9.

Shek, D. T. L., Siu, A. M. H., \& Lee, T. Y. (2007). The Chinese Positive Youth Development Scale: a validation study. Research on Social Work Practice, 17(3), 380-391. https://doi.org/10.1177 /1049731506296196.

Shek, D. T. L., Yu, L., Ma, C. M. S., Sun, R. C. F., \& Liu, T. T. (2013). Development of a credit-bearing service leadership subject for university students in Hong Kong. International Journal of Adolescent Medicine and Health, 25(4), 353-361. https://doi.org/10.1515/ijamh-2013-0033.

Shek, D. T. L., Yu, L., \& Ma, C. M. S. (2014a). The students were happy, but did they change positively? International Journal on Disability and Human Development, 13(4), 505-511. https://doi.org/10.1515 /ijdhd-2014-0348.

Shek, D. T. L., Yu, L., Wu, F. K. Y., \& Chai, W. Y. (2014b). General University Requirements at Hong Kong Polytechnic University: evaluation findings based on student focus groups. Assessment \& Evaluation in Higher Education, 40(8), 1017-1031. https://doi.org/10.1080/02602938.2014.960362.

Shek, D. T. L., Li, X., \& Liang, L.-Y. (2016a). A six-year longitudinal study of social competence amongst Chinese adolescents in Hong Kong. International Journal on Disability and Human Development, 15(4), 423-432. https://doi.org/10.1515/ijdhd-2017-5009. 
Shek, D. T. L., Liang, J., \& Lin, L. (2016b). Socio-demographic and family predictors of moral competence in Chinese adolescents in Hong Kong: a six-wave longitudinal study. International Journal on Disability and Human Development, 15(4), 433-442. https://doi.org/10.1515/ijdhd-2017-5010.

Shek, D. T. L., Yu, L., Wu, F. K. Y., Zhu, X., \& Chan, K. H. Y. (2016c). A 4-year longitudinal study of wellbeing of Chinese university students in Hong Kong. Applied Research in Quality of Life. https://doi. org/10.1007/s11482-016-9493-4.

Shek, D. T. L., Lin, L., Leung, H., \& Zhu, X. (2017). The impact of an intensive service leadership course in mainland China: objective outcome evaluation. International Journal of Child and Adolescent Health, 10(1), 63-71.

Shi, J.-h., \& Wen, W. (2012). Tsinghua University undergraduate education survey report, 2010. Tsinghua Journal of Education, 33(1), 6-16.

Snyder, T. D., \& Dillow, S. A. (2013). Digest of education statistics 2012 (NCES 2014-015). Washington D.C.: National Center for Education Statistics, Institute of Education Sciences, U.S. Department of Education.

Steedle, J. T. (2012). Selecting value-added models for postsecondary institutional assessment. Assessment \& Evaluation in Higher Education, 37(6), 637-652. https://doi.org/10.1080/02602938.2011.560720.

University Grants Committee (2004). Hong Kong higher education, to make a difference, to move with the times. http://www.ugc.edu.hk/eng/doc/ugc/publication/report/policy_document_e.pdf. Accessed 15 Feb 2017.

University Grants Committee (2016). Statistics home. http://cdcf.ugc.edu.hk/cdcf/searchStatSiteReport.do. Accessed Feb 152017.

Voyer, D., \& Voyer, S. D. (2014). Gender differences in scholastic achievement: a meta-analysis. Psychological Bulletin, 140(4), 1174-1204. https://doi.org/10.1037/a0036620.

Yu, Y., Yang, X., Yang, Y., Chen, L., Qiu, X., Qiao, Z., et al. (2015). The role of family environment in depressive symptoms among university students: a large sample survey in China. PLoS One, 10(12), e0143612. https://doi.org/10.1371/journal.pone.0143612.

Zlatkin-Troitschanskaia, O., Shavelson, R. J., \& Kuhn, C. (2015). The international state of research on measurement of competency in higher education. Studies in Higher Education, 40(3), 393-411. https://doi.org/10.1080/03075079.2015.1004241. 